\title{
Systems Biology of Meridians, Acupoints, and Chinese Herbs in Disease
}

\author{
Li-Ling Lin, ${ }^{1}$ Ya-Hui Wang, ${ }^{2}$ Chi-Yu Lai, ${ }^{2}$ Chan-Lao Chau, ${ }^{3}$ Guan-Chin Su, ${ }^{4}$ \\ Chun-Yi Yang, ${ }^{4}$ Shu-Ying Lou, ${ }^{1}$ Szu-Kai Chen, ${ }^{5}$ Kuan-Hao Hsu, ${ }^{5}$ Yen-Ling Lai, ${ }^{1}$ \\ Wei-Ming Wu, ${ }^{6}$ Jian-Long Huang, ${ }^{7}$ Chih-Hsin Liao, ${ }^{1}$ and Hsueh-Fen Juan ${ }^{1,5,7}$ \\ ${ }^{1}$ Department of Life Science, National Taiwan University, No. 1, Section 4, Roosevelt Road, Taipei 106, Taiwan \\ ${ }^{2}$ Graduate Institute of Epidemiology and Preventive Medicine, National Taiwan University, Taipei 100, Taiwan \\ ${ }^{3}$ Department of Bioenvironmental Systems Engineering, National Taiwan University, Taipei 106, Taiwan \\ ${ }^{4}$ Institute of Biochemical Sciences, National Taiwan University, Taipei 106, Taiwan \\ ${ }^{5}$ Institute of Molecular and Cellular Biology, National Taiwan University, No. 1, Section 4, Roosevelt Road, \\ Taipei 106, Taiwan \\ ${ }^{6}$ Department of Biochemical Science and Technology, National Taiwan University, Taipei 106, Taiwan \\ ${ }^{7}$ Graduate Institute of Biomedical Electronic and Bioinformatics, National Taiwan University, No. 1, Section 4, \\ Roosevelt Road, Taipei 106, Taiwan
}

Correspondence should be addressed to Hsueh-Fen Juan, yukijuan@ntu.edu.tw

Received 2 August 2012; Accepted 26 September 2012

Academic Editor: Wolfgang Schwarz

Copyright (C) 2012 Li-Ling Lin et al. This is an open access article distributed under the Creative Commons Attribution License, which permits unrestricted use, distribution, and reproduction in any medium, provided the original work is properly cited.

\begin{abstract}
Meridians, acupoints, and Chinese herbs are important components of traditional Chinese medicine (TCM). They have been used for disease treatment and prevention and as alternative and complementary therapies. Systems biology integrates omics data, such as transcriptional, proteomic, and metabolomics data, in order to obtain a more global and complete picture of biological activity. To further understand the existence and functions of the three components above, we reviewed relevant research in the systems biology literature and found many recent studies that indicate the value of acupuncture and Chinese herbs. Acupuncture is useful in pain moderation and relieves various symptoms arising from acute spinal cord injury and acute ischemic stroke. Moreover, Chinese herbal extracts have been linked to wound repair, the alleviation of postmenopausal osteoporosis severity, and anti-tumor effects, among others. Different acupoints, variations in treatment duration, and herbal extracts can be used to alleviate various symptoms and conditions and to regulate biological pathways by altering gene and protein expression. Our paper demonstrates how systems biology has helped to establish a platform for investigating the efficacy of TCM in treating different diseases and improving treatment strategies.
\end{abstract}

\section{Introduction}

According to traditional Chinese medicine (TCM), acupoints are linked in a network of meridians running along the surface of the body. The meridian system is a special channel network that consists of skin with a high concentration of nerves, various nociceptive receptors, and deeper connective tissues inside the body [1]. Moreover, " $q_{i}$ " (vital energy) in TCM is transferred by meridians, and its flow around the body can reflect the health status of individuals [2]. Acupoints are special locations in the body where the " $q_{i}$ " of viscera and meridians infuses and effuses. This phenomenon is thought to be similar to how signals are passed through neural networks. Acupoints are also considered reflection points (i.e., points on the body whose reflexes provide diagnostic information) for certain diseases and are the targets for clinical acupuncture [3].

Acupuncture is an alternative medicine methodology that originated in ancient China. It uses thin metal needles to pierce through skin into acupoints to regulate the flow of $q_{i}$ around the whole body [4]. Needling at appropriate points can induce effects in locations remote from the insertion 


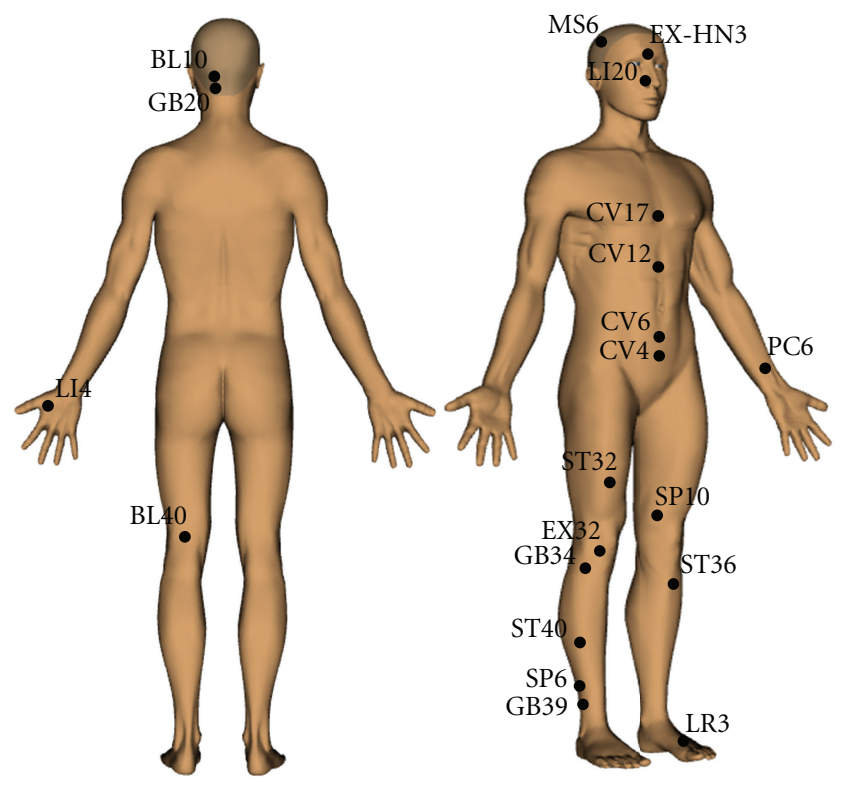

FIGURE 1: The approximate locations of acupoints on the human body reviewed in this paper. Images are created by Acu3D Ver.1.0.2011.0218.

site [5]. Many recent brain imaging studies have shown that acupuncture has a specific correlation with the human nervous system. Using functional magnetic resonance imaging (fMRI) to scan the brains of subjects undergoing needling, researchers found that different acupoints corresponded to different cerebral areas and conditioned reactions $[3,6]$. Therefore, it has the potential to provide therapy for many diseases. Recent studies have found that electroacupuncture (EA) improved the pathology of motor disorders in a Parkinsonian rat model by restoring homeostasis in the basal ganglia circuit $[7,8]$. In other reports, the effects of EA treatment on neuropathic pain [9], acute spinal cord injury [10], acute ischemic stroke [11], and reducing inflammation $[12,13]$ were also rigorously studied. We review the relevant literature below and have depicted the human acupoints described in this paper in Figure 1.

Another important aspect of TCM is Chinese herbal medicine (CHM), which has been used for thousands of years as a major preventive and therapeutic strategy against disease [14]. Currently, more than 3,200 species of medicinal plants are used in CHM treatments. A fundamental feature of TCM is TCM compound formulas, which are composed of many kinds of herbs and sometimes minerals or animal components, similar to a cocktail therapy [15]. Each TCM compound formula is usually designed to combat specific symptoms and combined with other herbs or prescriptions to tailor to individual needs. Herbal extracts have been investigated for use in treating various diseases and have been used as a complementary or alternative form of medical therapy for cancer patients [16-18]. In other studies that focus on chronic kidney disease [19], neurodegenerative disease [20], and diabetes mellitus [21], Chinese herbs have been reported to alleviate symptoms and mediate signal transduction.

Systems biology, which combines computational and experimental approaches to analyze complex biological systems, focuses on understanding functional activities from a systems-wide perspective [22]. With the advent of high-throughput global gene expression, proteomics, and metabolomic technologies, systems biology has become a viable approach for improving our knowledge of health and disease $[23,24]$. In this paper, we review recent research articles on acupuncture and Chinese herbal therapy performed in conjunction with omics technologies to analyze and investigate the regulatory mechanisms of the treatments and their therapeutic applications.

\section{Systems Biology and Omics Data}

Systems biology is the computational integration of huge datasets to explore biomolecular functional networks [22, 25]. The field offers many approaches and models for searching for biological pathways and predicting their effects and implications $[26,27]$. More recently, academic research has focused on developing basic informatics tools that can integrate large quantities of global gene expression, proteomic, and metabolomic data to mimic regulatory networks and cell function $[26,28]$. The principle of systems biology is to understand and compare physiology and disease, first from the level of molecular pathways and regulatory networks, then moving up through the cell, tissue, and organ, and finally whole organism levels $[29,30]$. It has the potential to provide new concepts to reveal unknown functions at all levels of the organism being studied.

Omics data helps to explore the different levels in systems biology from a holistic perspective. The suffix "-omics" is added to the object of study or the level of biological process to form new terms to describe that informationfor example, genomics from gene data, proteomics from protein data, metabolomics from metabolic data [31]. With 
rapid progress in sequencing and computational methods, omics techniques have become powerful tools for researching biological mechanisms and diseases and for interdisciplinary applications, for example, biologics, mathematics, and informatics [32-34].

\section{Genomic Studies of Acupuncture in Diseases}

Many individual transcriptional profiles of animals or patients have been mined to search for target molecules of acupuncture treatments. Candidate genes or pathways associated with the protective effect of acupuncture treatments have been revealed through genomic analysis for several diseases and symptoms. We list the acupoints and related symptoms in Table 1.

3.1. Analgesia. Acupuncture was reported to reduce pain during surgery in the 1950s [35] and can treat different types of pain in many cases $[36,37]$. Particularly, previous reports have indicated a major role for acupoint ST36, whose therapeutic properties include analgesia [38]. Gao et al. compared the hypothalamus transcriptional profiles of rats that responded or did not respond to EA analgesia treatment at ST36 [39]. They found that genes for glutamatergic receptors, ghrelin precursor peptides, the melanocortin 4 receptor, and neuroligin 1 may all be new targets for pain management. Moreover, Chae et al. found 375 genes showing significant variation in response to the analgesic effect of acupuncture (on LI4) [40]. Among these genes, cold shock domain protein A and kruppel-like factor 5 were identified as potential targets for investigating the mechanisms behind acupuncture-induced analgesia.

3.2. Antiaging. In an anti-aging study, Ding et al. analyzed the hippocampus gene expression profiles in senescenceaccelerated mice given acupuncture treatment [41]. Following applied acupuncture at the CV17, CV12, CV6, ST36, and SP10 acupoints, the researchers observed eight genes affected by age. They found that acupuncture could completely or partially alter the gene expression of heatshock proteins (Hsp84 and Hsp86) and Y-box binding protein 1-genes related to oxidative damage-in senescenceaccelerated mice, indicating that acupuncture may show promise in retarding aging in mammals.

3.3. Hypercholesterolemia. Li and Zhang stimulated C57BL/ $6 \mathrm{j}$ mice, which are used in diabetes and obesity research, at the ST40 acupoint and found that cholesterol $7 \alpha$ hydroxylase was upregulated following EA, while sodium taurocholate cotransporting polypeptide was downregulated [42]. Each of these variations in gene expression might alter the balance of cholesterol metabolism and reduce cholesterol by regulating bile salt biosynthesis and flux, respectively $[43,44]$.

3.4. Knee Osteoarthritis. Tan et al. compared the transcriptional profiles of four patients stimulated at the CV4, CV6, ST36, EX32, and GB34 acupoints [45]. They collected samples from the peripheral blood of patients after acupuncture
TABLE 1: List of the acupuncture points (acupoints) reviewed in this paper.

\begin{tabular}{|c|c|c|c|}
\hline $\begin{array}{l}\text { Acupoint } \\
\text { Chinese name }\end{array}$ & $\begin{array}{l}\text { Acupoint } \\
\text { name }\end{array}$ & Function/target & References \\
\hline Weizhong & BL40 & Acute ischemic stroke & {$[11]$} \\
\hline Tianzhu & BL10 & Acute ischemic stroke & {$[11]$} \\
\hline Guanyuan & CV4 & Knee osteoarthritis & {$[45]$} \\
\hline Qihai & CV6 & $\begin{array}{c}\text { Antiaging, } \\
\text { knee osteoarthritis }\end{array}$ & {$[41,45]$} \\
\hline Zhongwan & $\mathrm{CV} 12$ & Antiaging & {$[41]$} \\
\hline Danzhong & CV17 & Antiaging & {$[41]$} \\
\hline Yintang & EX-HN3 & Allergic rhinitis & {$[56]$} \\
\hline Xiyan & EX32 & Knee osteoarthritis & {$[45]$} \\
\hline Fengchi & GB20 & Acute ischemic stroke & {$[11]$} \\
\hline Yanglingquan & GB34 & $\begin{array}{l}\text { Knee osteoarthritis, } \\
\text { Parkinson's disease }\end{array}$ & $\begin{array}{c}{[45,49-} \\
52,63,64]\end{array}$ \\
\hline Xuanzhong & GB39 & $\begin{array}{l}\text { Spinal cord injury, } \\
\text { Parkinson's disease, }\end{array}$ & {$[46,64]$} \\
\hline Hegu & LI4 & $\begin{array}{l}\text { Allergic rhinitis, } \\
\text { analgesia, and acute } \\
\text { ischemic stroke }\end{array}$ & $\begin{array}{c}{[11,40,} \\
56]\end{array}$ \\
\hline Yingxiang & LI20 & Allergic rhinitis & {$[46,56]$} \\
\hline Taichong & LR3 & Parkinson's disease & {$[49,50]$} \\
\hline Motor Area & MS6 & Acute ischemic stroke & {$[11]$} \\
\hline Neiguan & PC6 & Acute ischemic stroke & {$[11]$} \\
\hline Sanyinjiao & SP6 & $\begin{array}{l}\text { Spinal cord injury, } \\
\text { acute ischemic stroke }\end{array}$ & {$[11,46]$} \\
\hline Xuehai & SP10 & Anti-aging & {$[41]$} \\
\hline Futu & ST32 & Spinal cord injury & {$[46]$} \\
\hline Zusanli & ST36 & $\begin{array}{l}\text { Neuropathic pain, } \\
\text { spinal cord injury, } \\
\text { immune modulation, } \\
\text { allergic rhinitis, } \\
\text { analgesia, } \\
\text { anti-aging, } \\
\text { knee osteoarthritis, } \\
\text { and acute ischemic } \\
\text { stroke }\end{array}$ & $\begin{array}{c}{[9,11,38-} \\
41,45- \\
47,53-56]\end{array}$ \\
\hline $\mathrm{Fe}$ & ST40 & Hypercholesterolemia & {$[42]$} \\
\hline
\end{tabular}

treatments. Among differentially expressed genes involved in the pathways, oxidative phosphorylation (ATP synthesis) was found in all patients. Analysis of profiles with respect the Kyoto Encyclopedia of Genes and Genomes (KEGG) pathway database showed that the majority of differentially expressed genes were associated with seven types of metabolic pathways, particularly the primary, cellular, and energy metabolism pathways. These results showed that acupuncture treatment may regulate gene expression to balance energy metabolism of knee osteoarthritis patients.

3.5. Neuronal Diseases. In a spinal cord injury (SCI) study, EA treatment on rats at four acupoints-ST36, GB39, ST32, 
and SP6 - was seen to restore sensory function by microarray analysis [46]. In this study, they found that extending the EA treatment time for SCI rats could result in more changes in gene expression. After EA stimulation, the gene expression of calcitonin gene-related polypeptide (CGRP) and neuropeptide Y (NPY) were up-regulated and functionally annotated with the recovery of sensory functions. Acupuncture treatment at ST36 has also been reported to reduce neuropathic pain. Using microarray analysis, opioid receptor sigma was one of differentially expressed genes and involved in opioid signaling which has been implicated in neuropathic pain and the analgesic effects of EA at ST36 in neuropathic pain model rats [47].

Parkinson's disease is a neurodegenerative disease caused by the death of dopaminergic neurons [48]. Several studies have performed acupuncture treatments on different acupoints in 1-methyl-4-phenyl-1, 2, 3, 6-tetrahydropyridine(MPTP-) induced Parkinson's models. These models were used to evaluate the effects of acupuncture treatment at the GB34 and LR3 acupoints by analyzing the transcriptional profiles from cervical spinal cord or brain bilateral striatal tissues $[49,50]$. Among the genes downregulated by acupuncture treatment, proplatelet basic protein (Ppbp) was functionally annotated with cytokine-cytokine receptor interaction pathways, and cytotoxic $\mathrm{T}$ lymphocyte-associated protein 2 alpha (Ctla2a) was associated with a pathway relevant to Parkinson's disease according to KEGG analysis [49]. Similar results were observed from substantia nigra tissue of MPTP mice following treatment at the GB34 acupoint [51]. In previous studies, myelin basic protein, a major constituent of the axonal myelin sheath, has been reported to be up-regulated in MPTP mice and Parkinson's patients stimulated at the GB34 acupoint [52]. In the bilateral striatal tissue of mice brain following acupuncture at the GB34 and LR3 acupoints, the gene expression levels of gap junction alpha 4 protein (Gja4) and tubulin alpha 8 (Tuba8) were down-regulated and annotated with the cell communication and gap junction pathway, respectively. Furthermore, an up-regulated gene, neurotrophin-3 (Ntf3), was annotated with the mitogen-activated protein kinases (MAPK) signaling pathway [50].

3.6. Immune Modulation and Allergic Rhinitis. Evidence from mouse models has demonstrated that EA or acupuncture stimulation at ST36 can modulate the immune response [53-55]. Two studies using a 2,4-dinitrophenylated keyhole limpet protein (DNP-KLH) immunized mouse model have shown that gene expression patterns can change in the spleen [55] and hypothalamus [54] after EA treatment. Using Sprague Dawley (SD) rats, Kim et al. found that the genes altered following EA at ST36 play crucial roles in natural killer cell activation in spleen tissue [53]. However, the effects of EA treatments remain diverse, partly because of variation in immune responses when triggered in different types of tissues or models (e.g., DNP-KLH immunized mice versus SD rats).

Acupuncture treatment has also demonstrated some effectiveness against allergic rhinitis in clinical settings, presumably through immune modulation $[56,57]$. Allergic rhinitis occurs when an allergen is inhaled and generates an immune response in an individual. Its symptoms can be reduced by acupuncture treatment at the EX-HN3, LI4, LI20, and ST36 acupoints [56]. The effectiveness of the treatment could be accounted for by modulation of proand anti-inflammatory genes observed through microarray analyses of blood samples. Immune responses to allergic rhinitis may vary depending on types of allergen. Shiue et al. have used the Phadiatop $(\mathrm{Ph})$ assay, an effective screening tool that detects a diverse range of allergens, to demonstrate that patients with $\mathrm{Ph}$-positive $(+)$ and $\mathrm{Ph}-$ negative (-) allergic rhinitis display different gene expression profiles after acupuncture treatment [57]. A hierarchical clustering analysis revealed that three gene groups-those for active immune response, regulatory $\mathrm{T}$ cell differential, and apoptosis-were differentially expressed in the $\mathrm{Ph}(+)$ and $\mathrm{Ph}(-)$ patients after treatment [57]. These results also indicate the importance of personalized medicine for future investigations.

\section{Proteomic Studies of Acupuncture in Diseases}

Proteomic technologies, such as two-dimensional electrophoresis (2-DE), can screen for proteins differentially expressed between individuals responsive and nonresponsive to acupuncture treatments. These proteins were identified by various mass spectrometry (MS) techniques, and their related pathways were explored to determine the mechanism of the acupuncture treatments. The results clarify the relationships between different acupoints and functions (Table 1).

4.1. Acute Ischemic Stroke. EA efficacy has been studied by comparing levels of serum proteins in response to EA or drug treatments in acute ischemic stroke patients [11]. Patients were treated with EA at eight acupoints (MS6, BL10, GB20, LI4, PC6, B40, SP6, and ST36) once daily for ten consecutive days. The protein profiles were analyzed using 2DE; SerpinG1 was up-regulated, while gelsolin, complement component $1(\mathrm{C} 1), \mathrm{C} 3, \mathrm{C} 4 \mathrm{~B}$, and beta-2-glycoprotein I were all down-regulated. Other studies have indicated that platelet C4 expression is associated with acute ischemic stroke by comparing serum proteins from healthy individuals and ischemic stroke patients [58].

4.2. Neuronal Diseases. Using matrix-assisted laser desorption/ionization time-of-flight mass spectroscopy (MALDI TOF-MS) and subsequent protein database mining, Li et al. identified fifteen candidate proteins whose expression levels varied with acupuncture treatment for SCI [59]. Among them, annexin A5 (ANXA5) and collapsin response modifier protein 2 (CRMP2) were determined to be beneficial for neuronal survival and axonal regeneration. ANXA5 is a member of the annexin superfamily of calcium- and phospholipid-binding proteins, which are related to apoptosis and inflammation [60]. CRMP2 is a member of the collapsin response mediator protein family and is expressed 
exclusively in the nervous system, especially during development [61]. Additionally, among up-regulated proteins, heat shock protein beta-1 (HSPB1) has a reported role in cell stress/neuroprotection as well as in axonal regeneration [62]. These results reveal the potential for proteomics research to supplement and guide the treatment of SCI with acupuncture in future research.

Moreover, Sung et al. applied EA at ST36 in a SD rat model, and subsequent 2-DE was used to identify signaling pathways involved in neuropathic pain [9]. Thirtysix differentially expressed proteins were identified in the neuropathic pain model, and the normal expression levels of their corresponding genes could be restored following EA treatment. Furthermore, Jeon et al. performed EA at GB34 in an MPTP mouse model of Parkinson's disease [63]. They observed restoration of behavioral impairment and rescued tyrosine hydroxylase-positive dopaminergic neurodegeneration after the treatment. In previous studies, the expression of myelin basic protein can also be restored to normal levels after EA treatment [63]. Kim et al. performed similar studies at GB34 and GB39 [64]. They identified thirteen differentially expressed proteins using MS, and four of these proteins-cytosolic malate dehydrogenase, munc18-1, hydroxyacylglutathione hydrolase, and cytochrome c oxidase subunit $\mathrm{Vb}$-were restored to normal expression levels following EA treatment. These proteins are involved in cell metabolism, and may reduce MPTP-induced dopaminergic neuronal destruction by decreasing oxidative stress. Taken together, these results suggest that acupuncture treatment is likely to have a neuroprotective effect on neuronal diseases through cell metabolic and nervous tissue developmental pathways, among others.

\section{Genomic Studies of Chinese Herbs in Diseases}

Many studies have investigated genes impacted by Chinese herb extracts from transcriptional profiles after treatment and analyzed their functions using pathway databases. These results were used to evaluate whether Chinese herb extracts could be used as a complementary drug to treat specific symptoms. Here, we review Chinese herbal treatment-related studies that incorporated genomic analysis and interpret the efficacy of Chinese herb extracts for various symptoms and conditions (Table 2).

5.1. Immunomodulatory Function. It is generally agreed that the fungus Ganoderma lucidum contains an abundance of polysaccharides with immunostimulatory properties [65], and these have been investigated using human CD14 (+) (cluster of differentiation 14) derived dendritic cells $[66,67]$. Dendritic cells are antigen-presenting cells that play a critical role in the regulation of the adaptive immune response. A comparison of transcriptional profiles from the polysaccharide of G. lucidum-treated dendritic cells and untreated dendritic cells showed a decrease in the expression of some phagocytosis-related genes, for example, CD36, CD206, and CD209. The expression of proinflammatory chemokines was increased, that is, chemokine (C-C motif) ligands (CCL)
CCL20, CCL5, and CCL19; interleukins (IL) IL-27, IL-23A, IL-12A, and IL-12B; costimulatory molecules CD40, CD54, CD80, and CD86 [67]. Additionally, altered expression levels of CD209, CCL20, CCL5, IL-27, CD54, CD80, and CD86 in cells after treatment with F3 (a polysaccharide fraction extracted from lingzhi) have been observed by Lai et al., with CD209 expression down-regulated proportional to treatment time [66]. Another study investigated the treatment of human CD14+ monocytes with polysaccharide fractions extracted from North American ginseng [68]. The MAPK (extracellular regulated protein kinases-1/2), phosphoinositide-3-kinase, p38, and nuclear factor-kappaB $(\mathrm{NF}-\kappa \mathrm{B})$ cascades are key signaling pathways that may trigger immunomodulatory functions, as determined by Ingenuity Pathway Analysis [68]. With regard to other extracts, Cheng et al. reported that the NF- $\kappa \mathrm{B}$ pathway was up-regulated in THP-1 by treatment with ethanol extracts of G. sinense, but not by G. lucidum [69]. Moreover, protosappanin A treatment (an ethanol extract of Caesalpinia sappan) has been reported to induce an immunosuppressive effect via the NF- $\kappa$ B pathway in a heart transplantation rat model [70].

5.2. Wound Repair. Herbal formulas containing extracts of Astragali radix, Rehmanniae radix, and Angelica sinensis show potential therapeutic benefits for wound repair [72]. For example, the formula NF3, which consists of a $2: 1$ ratio of $A$. radix and $R$. radix, has been found to affect cell proliferation, angiogenesis, extracellular matrix formation, and inflammation in the Hs27 skin fibroblast cell line through microarray analysis [72]. Another study in human skin substitutes revealed that SBD.4 extracts of A. sinensis possesses skin- and wound-healing activity [73]. After SBD.4 stimulation, the gene expression of collagen XVI and XVII, laminin $\gamma$-2 and 5, claudin 1 and 4, hyaluronan synthase 3, superoxide dismutase 2, and heparin-binding EGF was upregulated and ADAM 9 was down-regulated in EpiDermFT skin substitute tissues. The elevation of collagen XVI and XVII can enhance collagen fibril organization and the reduction of ADAM9 may stimulate collagen deposition [89, 90]. These results suggest that these skin- and wound-healing related genes function in cell-substrate junction assembly.

5.3. Postmenopausal Osteoporosis. Traditional Chinese herbalists have been treating patients with chronic kidney disease for thousands of years [19]. The effect of an herbal mixture consisting of Herba Epimedii, Fructus Ligustri Lucidi, and Fructus Psoraleae was investigated in aged ovariectomy and calcium deficiency-induced osteoporotic rats [74]. A comparison of the transcriptional profiles between nontreated and herbal formula-treated ovariectomized rats found that some genes specifically activated by the herbal mixture, such as prostaglandin EP3 receptor and osteoprotegerin, were involved in bone remodeling and bone protection. Moreover, they identified the involvement of estrogen-related proteins and suggested that the herbal formula may act like estrogens.

5.4. Diabetes Mellitus. Type 2 diabetes mellitus (T2DM) is characterized by insufficient insulin secretion and insulin 
TABLE 2: List of Chinese herbal studies that have incorporated genomic and proteomic analysis.

\begin{tabular}{|c|c|c|c|}
\hline Authors & Herb name & Extracts & Common functions \\
\hline $\begin{array}{l}\text { Sliva [65], } \\
\text { Lai et al. [66], } \\
\text { Lin et al. [67], } \\
\text { Cheng et al. [71] }\end{array}$ & G. lucidum (lingzhi) & Polysaccharide fraction/F3 & $\begin{array}{l}\text { Immunomodulatory, } \\
\text { antitumor activity }\end{array}$ \\
\hline Cheng et al. [69] & G. sinense (lingzhi) & Ethanol extracts & Immunomodulatory \\
\hline Wu et al. [70] & C. sappan & Protosappanin A & Immunomodulatory \\
\hline Zhang et al. [72] & A. Radix and R. Radix & $\begin{array}{l}\text { NF3 (A. Radix and R. Radix } \\
\text { in the ratio of } 2: 1 \text { ) }\end{array}$ & Wound repair \\
\hline Zhao et al. [73] & A. Sinensis & SBD.4 & Wound repair \\
\hline Sun et al. [74] & $\begin{array}{c}\text { Herba Epimedii, } \\
\text { Fructus Ligustri Lucidi, and } \\
\text { Fructus Psoraleae }\end{array}$ & & Postmenopausal osteoporosis \\
\hline Han et al. [21] & C.A. Meyer & CK & Diabetes mellitus \\
\hline $\begin{array}{l}\text { Luo et al. [75], } \\
\text { King and Murphy } \\
{[76]}\end{array}$ & $\begin{array}{l}\text { American ginseng } \\
\text { (P. quinquefolius L.) }\end{array}$ & Ginsenoside Rg3/ginseng extracts & Antitumor activity \\
\hline $\begin{array}{l}\text { Hara et al. [77], } \\
\text { Iizuka et al. [78] }\end{array}$ & C. rhizome & Benzodixoloquinolizine alkaloids/berberine & Anti-tumor activity \\
\hline Wang et al. [79] & L. rubescens & Oridonin & Anti-tumor activity \\
\hline $\mathrm{Xu}$ et al. [80] & Franquet & TBMS1 & Anti-tumor activity \\
\hline Cheng et al. [81] & R. paridis & RPTS & Anti-tumor activity \\
\hline Yue et al. [82] & P. ginseng & $\operatorname{Rg} 1$ & Angiogenesis \\
\hline Konkimalla et al. [83] & Artemisinin & & Nitric oxide biosynthesis \\
\hline Su et al. $[20,84]$ & P. suffruticosa & Paeonol & Neurodegenerative disease \\
\hline Wang et al. [85] & S. miltiorrhiza & SAL or TAN & Acute myocardial infarction \\
\hline Lo et al. [86] & U. rhynchophylla & & Convulsive disorders \\
\hline Hung et al. $[87,88]$ & S. miltiorrhiza & SMAE & Cardiovascular disorder \\
\hline
\end{tabular}

resistance, such that the liver lacks the ability to regulate glycolysis and gluconeogenesis [91]. Han et al. compared gene expression profiles of C57BL/KsJ- $d b / d b$ mice (insulinresistant model of insulin-dependent diabetes and obesity) following treatment with compound $\mathrm{K}(\mathrm{CK})$, a final metabolite of Panax ginseng C.A. Meyer [21]. They found that some differentially expressed genes in liver tissue were associated with glycolysis/gluconeogenesis and pentose phosphate pathways, for example, upregulation of aldolase 2, B isoform and phosphogluconate dehydrogenase for glycolysis and pentose phosphate pathways, and downregulation of fructose bisphosphatase 1 for gluconeogenesis pathways after CK treatment. In adipose tissue, on the other hand, they found differentially expressed genes there was linked to adipocytokine signaling and fatty acid synthesis/metabolism pathways, for example, upregulation of peroxisome proliferatoractivated receptor gamma for adipocytokine signaling and fatty acid synthase for fatty acid synthesis pathways after CK treatment.

Plasma adiponectin, a hormone responsible for increasing neoglucogenesis, is secreted from adipocytes and might play a key role in linking obesity, insulin resistance, and the T2DM syndrome. A higher adiponectin expression has been observed in conjunction with lowered obesity levels in human studies [92]. Furthermore, Fu et al. have found that adiponectin increases total glucose transporter 4 expression, which can aid in the response to insulin at the plasma membrane [93]. These results suggest that CK might be a potential target for antidiabetic drugs.

5.5. Antitumor Activity. Chinese herbs have been known to possess anti-tumor activity, and some studies have investigated this functionality and its mechanisms in cancer treatments. F3-treated human leukemia THP-1 cells have been found to undergo apoptosis through death receptor pathways as determined through microarray analysis [71]. Furthermore, F3 induces macrophage-like differentiation by caspase cleavage and p53 activation in THP-1 cells [94]. Another study using a microarray approach determined that $25 \%$ of genes regulated by two lingzhi ( $G$. lucidum and $G$. sinense) was determined to be similar [69]. G. sinense was observed to regulate inflammation and immune response pathways, while G. lucidum appeared to increase the expression levels of NF- $\kappa \mathrm{B}$ pathway genes. Therefore, lingzhi appears to have efficacy as an anti-tumor agent against THP-1 cells.

Other Chinese herbs have also been associated with anti-tumor effects [95-101]. Two studies have shown that 
American ginseng (Panax quinquefolius L.) extracts can inhibit tumor growth in HCT-116 [75] and MCF-7 cells [76]. A-kinase (PRKA) and anchor protein 8-like (AKAPA8L) gene expression were up-regulated, and phosphatidylinositol transfer protein alpha (PITPNA) gene expression was down-regulated after ginsenoside Rg3 treatment in HCT116 cells [75]. The inhibition of the MAPK pathway and the up-regulation of Raf-1 kinase inhibitor protein (RKIP) expression were determined in the ginseng extract of hot water-extracted American ginseng-treated MCF-7 cells [76]. These genes have anticancer potential and are considered to be involved in anti-tumor mechanism of America ginseng. A comparison of transcriptional profiles between mouse macrophage RAW 264.7 cells before and after artemisinin treatments [83] found that the differentially expressed genes were most associated with the nitric oxide, cAMP, and Wnt/beta-catenin pathways. They suggested that the tumor regulation function of artemisinin might arise from its effect on nitric oxide biosynthesis. Nitric oxide has been proved that it can suppress tumorigenesis [102].

In another study, Hara et al. examined eight benzodixoloquinolizine alkaloids extracted from Coptidis rhizome and assessed the strength of their antiproliferative activity in eight human pancreatic cancer cell lines [77]. These results indicated that berberine is the major compound behind boosting the anti-proliferative response. However, the antitumor effect of berberine isolated from C. rhizome was poorer than that of whole C. rhizome, suggesting other components of the fungus are to some degree responsible as well [78]. MCF-7 cells treated with Coptidis extracts also displayed increased activation of anti-tumor pathways. Two critical anti-tumor cytokines were identified-interferon- $\beta$ and tumor necrosis factor- $\alpha$ - and Coptidis extracts were also found to induce cell growth arrest and apoptosis [103]. These studies suggest that C. rhizome or Coptidis extracts are able to inhibit cell proliferation by reducing tumor cell growth and promoting apoptosis.

5.6. Angiogenesis. Some Chinese herbs have been reported to promote angiogenesis. Ginseng refers to both Panax ginseng C.A. Meyer and Panax quinquefolius L. (Araliaceae), which contain similar components. Rg1, a P. ginseng extract, can promote angiogenesis by modulating cytoskeletal-related genes and enhancing endothelial nitric oxide synthase activities in human umbilical vein endothelial cells (HUVEC) [82]. Chan et al. also illustrated that Rg1-induced downregulation of miR-214 led to an increase in the expression of eNOS in HUVEC through miRNA microarray analysis [104]. Taken together, the findings suggest that Rg1, the major component ginosenoside from P. ginseng, can promote angiogenesis in HUVEC.

5.7. Cardiovascular Disease. Salvia miltiorrhiza is widely used for human cardiovascular disorders in Asia, but the cellular mechanism by which it attenuates the growth of aortic smooth muscle under oxidative stress remains unclear. Salvianolic acid (SAL) or tanshinone (TAN) purified from S. miltiorrhiza was used to treat acute myocardial infarction in Wistar rats [85]. SAL decreases the gene expression of apoptosis-related genes at in a later period after ischemia, for example, BCL2 modifying factor (Bmf). TAN decreases the gene expression of intracellular calcium pathways-related genes at an early stage after ischemic injury, for example, voltage-dependent calcium channel alpha 1 (CACNA1). Intracellular calcium and apoptosis pathways have been reported to be associated with ischemic cardiac injury and repair $[105,106]$. These results suggest that SAL and TAN could be used to prevent injury and involved in after injury repair of acute myocardial infarction.

5.8. Neuronal Diseases. Su et al. compared gene expression profiles of $\mathrm{H}_{2} \mathrm{O}_{2}$-exposed human neuroblastoma SH-SY5Y cells following treatment with paeonol, which is extracted from Paeonia suffruticosa $[20,84]$. They identified that the extract up-regulated the mature T-cell gene set and found that paeonol was able to reduce $\mathrm{H}_{2} \mathrm{O}_{2}$-induced NF- $\kappa \mathrm{B}$ activity. These data indicate that paeonol might have antioxidative related properties and could be used to treat neurodegenerative diseases, for example, Alzheimer's disease [107].

\section{Proteomic Studies of Chinese Herbs in Diseases}

Compared with studies investigating Chinese herbs using genomic analysis, proteomic analytic studies have been performed far less and on fewer herbs. Tumors and convulsive disorders are the major subjects of analysis by proteomic technologies to date. The Chinese herbs used for these conditions and related references are documented in Table 2.

6.1. Antitumor Activity. HepG2 liver cancer cells were treated with oridonin extracted from Isodon rubescens and analyzed by 2-DE and MALDI-TOF-MS [79]. Proteomic data showed that expression levels of heat shock $70 \mathrm{kDa}$ protein 1 , Stilh, and hnRNP-E1 were altered after treatment; these proteins are associated with apoptosis pathways. An extract from Franquet (Cucurbitaceae), tubeimoside-1 (TBMS1), has also been used as an anticancer treatment [108]. Xu et al. found 15 proteins differentially expressed between TBMS-treated or -untreated HeLa cells through MALDI-TOF-MS analysis [80]. These proteins were associated with mitochondrial dysfunction and ER stress-induced cell death pathways and participated in TBMS1-induced cytotoxicity [80].

The major component of Rhizoma paridis, Rhizoma paridis total saponin (RPTS), is responsible for the antitumor effects of this herb. Using MALDI-TOF-MS, Cheng et al. identified 15 proteins altered in HepG2 cells differentially expressed between RPTS-treated or untreated HepG2 cells, with most of them implicated in tumor initiation, promotion, and progression [81]. These results suggest that proteomic approaches could be useful tools to elucidate pharmacological mechanisms responsible for anti-cancer drug activities.

Moreover, Hung et al. found that S. miltiorrhiza aqueous extract (SMAE) inhibited the proliferation of rat aortic 
smooth muscle cell line A10 under homocysteine (Hcy)induced oxidative stress $[87,88]$. Furthermore, the intracellular reactive oxygen species concentration significantly decreased in A10 cells after SMAE treatment. Using MALDITOF-MS, the researchers suggested that the SMAE-induced inhibition of growth in Hcy-stimulated A10 cells occurred via the PKC/MAPK-dependent pathway $[87,88]$.

6.2. Convulsive Disorders. Uncaria rhynchophylla (UR) and its major component, rhynchophylline, have demonstrated effectiveness in treating convulsive disorders [109]. Lo et al. used SD rats with kainic acid (KA)-induced epileptic seizures and treated them with UR [86]. They then analyzed proteomic profiles from the frontal cortex and hippocampus of rat brain tissues and identified proteins differentially expressed between treated and untreated tissue. Macrophage migration inhibitory factor (MIF) and cyclophilin A were down-regulated and restored to normal levels in epileptic seizure rats after UR treatment. MIF has been considered as a counterregulator of normal neuronal actions and increases its expression level to reduce the chronotropic actions in $\mathrm{SD}$ rats [110]. Cyclophilin A is a phylogenetically-conserved protein and regulates immunosuppression [111]. These results showed that MIF and cyclophilin A involved in the mechanism of anticonvulsive effect of UR.

\section{Metabolomics Studies of Chinese Herbs in Diseases}

Another platform for systems biology research is metabolomics, involving the study of targeted small molecule metabolites (<1500 Da). In 1998, the metabolome was first introduced in the elucidation of yeast gene function [112]. However, the application of this concept can be traced back to the development of traditional medicine; while metabonomics chemically tracks metabolites in urine, feces, and so forth, traditional medicine used color, smell, and taste to facilitate diagnoses. Over genomics and proteomics, metabolomics can provide a more solid link between genotype and phenotype.

7.1. NMR-Based Metabolomics Analysis. NMR-based metabolomics is an attractive method for the study of medicinal herb efficacy on disease symptoms. Using this method, nonselective and comprehensive analysis was performed on ginkgo extracts [113]. Moreover, Zhang et al. found that ginkgo extracts have multidirectional lipid-lowering effects on the rat metabonome [114]. They suggested that ginkgo extracts possess metabolomic functions, including limitation of cholesterol absorption, inactivation of HMGCoA, and favorable regulation of essential polyunsaturated fatty acid profiles [114].

7.2. Liquid Chromatography (LC)-TOF MS-Based Metabolomics. LC-MS-based metabolomics have been explored in many studies to date. Tan et al. performed LC-TOF MS to investigate the metabolites of aconitum alkaloids in rat urine after oral administration of aconite root extracts [115].
They found 10 metabolites and 24 parent components and suggested that metabolomic approaches may prove useful in exploring the efficacy of CHM. Moreover, Yan et al. investigated the antiaging effect of flavones contained in Epimedium extract in rats through LC-MS [116]. They were able to identify differences in multiple changed agerelated metabolites in serum, including carnosine, ergothioneine, unsaturated fatty acids, saturated fatty acids, and nucleotides. The expression levels of these age-related proteins were restored to levels found in younger rats after Epimedium treatment.

Terpenoids, a group of important secondary metabolites in plants, are found in Ganoderma sp., which have high cytotoxic and anti-tumor activity. Ganoderiol F, a tetracyclic triterpene, has been analyzed by LC/MS/MS and administered to rats for metabolomics and pharmacokinetics experiments [117]. Analysis of the metabolites of ganoderiol F by HPLC/MS/MS from orally or i.v.-treated rats showed good viability and low acute toxicity. According to these reports, ganoderiol F may show potential as an anti-cancer drug.

\section{Summary and Future Perspectives}

In this paper, we described and discussed omics research to date combined with acupuncture or CHM, performed at the systems biology level. We found that the ST36 acupoint is the most widely used acupoints, and that it has multiple therapeutic functions and targets, including spinal cord injury [46], allergic rhinitis [56], analgesia [38], neuropathic pain $[9,47]$, antiaging $[41]$, knee osteoarthritis [45], and acute ischemic stroke [11]. Different from other therapies, acupuncture treatments show variation in the transcriptional profiles and perceived effect of their subjects, whether rats [39] or humans [40]. Gao et al. reported that approximately $30 \%$ of rats demonstrated no analgesic effects during EA [39]. Similarly, Chae et al. reported that $40 \%$ of their participants felt only low analgesic effects during acupuncture, an observation that is more likely caused by genetic variation rather than differences in psychology [40]. Individual variance in treatment response is becoming an important issue when deciding whether it is suitable or not to administer acupuncture therapy. Based on this paper results, we suggest that system biology approaches can be performed to construct exhaustive clinical data of patients with acupuncture or CHM treatments, for example, upregulated or down-regulated genes of $\mathrm{Ph}(+)$ or $\mathrm{Ph}(-)$ allergic rhinitis patients with acupuncture treatments, and provide useful information for improving future therapeutic strategies. In term of acupuncture treatment, one acupoint commonly used for different symptoms, for example, LI4 acupoint could be performed for allergic rhinitis, analgesia, and acute ischemic stroke. Compared with acupuncture treatments, Chinese herbal treatments are more often investigated for their effectiveness on specific diseases, and studies focus on the pharmacological mechanisms of different herbal extracts, for example, benzodixoloquinolizine alkaloids has anti-tumor activity [77] or CK has anti-diabetic efficacy [21]. In summary, we suggest appropriate therapies-whether 


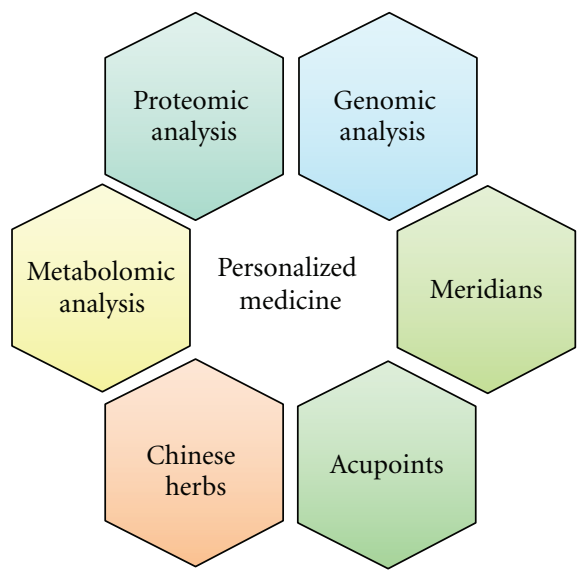

FIgURE 2: The composition of "personalized medicine in TCM." Combining genomic, proteomic, and metabolomic information can provide more comprehensive strategies for TCM therapies.

acupuncture, TCM, or a combination-can be personalized to individuals through analyzing their transcriptional or proteomic profiles (Figure 2). "Personalized medicine in TCM" can be developed even further and provide important information for therapeutic strategies in managing various diseases and conditions.

\section{Acknowledgments}

This work was supported by the National Taiwan University Cutting-Edge Steering Research Project (101R7602C3) and the National Science Council of Taiwan (NSC99-2621-B010-001-MY3, and NSC99-2621-B-002-005-MY3).

\section{References}

[1] P. C. W. Fung, "Probing the mystery of Chinese medicine meridian channels with special emphasis on the connective tissue interstitial fluid system, mechanotransduction, cells durotaxis and mast cell degranulation," Chinese Medicine, vol. 4, article 10, 2009.

[2] S. J. Birch and R. L. Felt, Understanding Acupuncture, Churchill Livingstone, New York, NY, USA, 1999.

[3] L. Bai, J. Tian, C. Zhong et al., "Acupuncture modulates temporal neural responses in wide brain networks: evidence from fMRI study," Molecular Pain, vol. 6, article 73, 2010.

[4] M. V. Madsen, P. C. Gøtzsche, and A. Hróbjartsson, “Acupuncture treatment for pain: systematic review of randomised clinical trials with acupuncture, placebo acupuncture, and no acupuncture groups," BMJ, vol. 338, p. a3115, 2009.

[5] H. M. Langevin and J. A. Yandow, "Relationship of acupuncture points and meridians to connective tissue planes," Anatomical Record, vol. 269, no. 6, pp. 257-265, 2002.

[6] J. Kong, T. J. Kaptchuk, G. Polich et al., "An fMRI study on the interaction and dissociation between expectation of pain relief and acupuncture treatment," NeuroImage, vol. 47, no. 3, pp. 1066-1076, 2009.

[7] J. Jia, B. Li, Z. L. Sun, F. Yu, X. Wang, and X. M. Wang, "Electro-acupuncture stimulation acts on the basal ganglia output pathway to ameliorate motor impairment in parkinsonian model rats," Behavioral Neuroscience, vol. 124, no. 2, pp. 305-310, 2010.

[8] J. Jia, Z. Sun, B. Li et al., "Electro-acupuncture stimulation improves motor disorders in Parkinsonian rats," Behavioural Brain Research, vol. 205, no. 1, pp. 214-218, 2009.

[9] H. J. Sung, Y. S. Kim, I. S. Kim et al., "Proteomic analysis of differential protein expression in neuropathic pain and electroacupuncture treatment models," Proteomics, vol. 4, no. 9, pp. 2805-2813, 2004.

[10] X. C. Yuan, J. L. Song, G. H. Tian, S. H. Shi, and Z. G. Li, "Proteome analysis on the mechanism of electroacupuncture in relieving acute spinal cord injury at different time courses in rats," Chinese Acupuncture \& Moxibustion, vol. 34, no. 2, pp. 75-82, 2009.

[11] S. Pan, X. Zhan, X. Su, L. Guo, L. Lv, and B. Su, "Proteomic analysis of serum proteins in acute ischemic stroke patients treated with acupuncture," Experimental Biology and Medicine, vol. 236, no. 3, pp. 325-333, 2011.

[12] J. Q. Fang, E. Aoki, Y. Yu, T. Sohma, T. Kasahara, and T. Hisamitsu, "Inhibitory effect of electroacupuncture on murine collagen arthritis and its possible mechanisms," In Vivo, vol. 13, no. 4, pp. 311-318, 1999.

[13] S. P. Zhang, J. S. Zhang, K. K. L. Yung, and H. Q. Zhang, "Non-opioid-dependent anti-inflammatory effects of low frequency electroacupuncture," Brain Research Bulletin, vol. 62, no. 4, pp. 327-334, 2004.

[14] S. Fulder, The Handbook of Alternative and Complementary Medicine, Oxford University Press, Oxford, UK, 1996.

[15] X. Xu, K. You, X. Bao, and K. Kang, Essentials of Traditional Chinese Medicine English-Chinese Encyclopedia of Practical Tcm, Higher Education Press, Beijing, China, 1991.

[16] M. A. Richardson, T. Sanders, J. L. Palmer, A. Greisinger, and S. E. Singletary, "Complementary/alternative medicine use in a comprehensive cancer center and the implications for oncology," Journal of Clinical Oncology, vol. 18, no. 13, pp. 2505-2514, 2000.

[17] S. Gözüm, A. Tezel, and M. Koc, "Complementary alternative treatments used by patients with cancer in Eastern Turkey," Cancer Nursing, vol. 26, no. 3, pp. 230-236, 2003.

[18] O. DePeyer, Herbal Extracts Help Fight Cancer, Nature News, 2000. 
[19] K. Wojcikowski, D. W. Johnson, and G. Gobe, "Herbs or natural substances as complementary therapies for chronic kidney disease: ideas for future studies," Journal of Laboratory and Clinical Medicine, vol. 147, no. 4, pp. 160-166, 2006.

[20] S. Y. Su, C. Y. Cheng, T. H. Tsai, C. Y. Hsiang, T. Y. Ho, and C. L. Hsieh, "Paeonol attenuates $\mathrm{H}_{2} \mathrm{O}_{2}$-induced NF- $\kappa$ Bassociated amyloid precursor protein expression," American Journal of Chinese Medicine, vol. 38, no. 6, pp. 1171-1192, 2010.

[21] G. C. Han, S. K. Ko, J. H. Sung, and S. H. Chung, "Compound $\mathrm{K}$ enhances insulin secretion with beneficial metabolic effects in $\mathrm{db} / \mathrm{db}$ mice," Journal of Agricultural and Food Chemistry, vol. 55, no. 26, pp. 10641-10648, 2007.

[22] H. F. Juan and H. C. Huang, System Biology: Applications in Cancer-Related Research, World Scientific, Singapore, 2012.

[23] Z. L. Whichard, C. A. Sarkar, M. Kimmel, and S. J. Corey, "Hematopoiesis and its disorders: a systems biology approach," Blood, vol. 115, no. 12, pp. 2339-2347, 2010.

[24] Y. Rudy, M. J. Ackerman, D. M. Bers et al., "Systems approach to understanding electromechanical activity in the human heart a national heart, lung, and blood institute workshop summary," Circulation, vol. 118, no. 11, pp. 1202-1211, 2008.

[25] H. Y. Chuang, M. Hofree, and T. Ideker, "A decade of systems biology," Annual Review of Cell and Developmental Biology, vol. 26, pp. 721-744, 2010.

[26] E. C. Butcher, E. L. Berg, and E. J. Kunkel, "Systems biology in drug discovery," Nature Biotechnology, vol. 22, no. 10, pp. 1253-1259, 2004.

[27] C. W. Hu, Y. L. Chang, S. J. Chen et al., "Revealing the functions of the transketolase enzyme isoforms in Rhodopseudomonas palustris using a systems biology approach," PloS One, vol. 6, no. 12, article e28329, 2011.

[28] R. Hall, M. Beale, O. Fiehn, N. Hardy, L. Sumner, and R. Bino, "Plant metabolomics: the missing link in functional genomics strategies," Plant Cell, vol. 14, no. 7, pp. 1437-1440, 2002.

[29] H. V. Westerhoff and B. O. Palsson, "The evolution of molecular biology into systems biology," Nature Biotechnology, vol. 22, no. 10, pp. 1249-1252, 2004.

[30] C. C. Lin, J. T. Hsiang, C. Y. Wu, Y. J. Oyang, H. F. Juan, and H. C. Huang, "Dynamic functional modules in co-expressed protein interaction networks of dilated cardiomyopathy," BMC Systems Biology, vol. 4, article 138, 2010.

[31] D. Greenbaum, N. M. Luscombe, R. Jansen, J. Qian, and M. Gerstein, "Interrelating different types of genomic data, from proteome to secretome: 'Oming in on function," Genome Research, vol. 11, no. 9, pp. 1463-1468, 2001.

[32] L. L. Lin, H. C. Huang, and H. F. Juan, "Discovery of biomarkers for gastric cancer: a proteomics approach," Journal of Proteomics, vol. 75, no. 11, pp. 3081-3097, 2012.

[33] C. C. Lin, Y. J. Chen, C. Y. Chen, Y. J. Oyang, H. F. Juan, and H. C. Huang, "Crosstalk between transcription factors and microRNAs in human protein interaction network," BMC Systems Biology, vol. 6, article 18, 2012.

[34] C. W. Tseng, C. C. Lin, C. N. Chen, H. C. Huang, and H. F. Juan, "Integrative network analysis reveals active microRNAs and their functions in gastric cancer," BMC Systems Biology, vol. 5, article 99, 2011.

[35] G. A. Ulett, J. Han, and S. Han, "Traditional and evidencebased acupuncture: history, mechanisms, and present status," Southern Medical Journal, vol. 91, no. 12, pp. 1115-1120, 1998.
[36] S. L. Cantwell, "Traditional Chinese veterinary medicine: the mechanism and management of acupuncture for chronic pain," Topics in Companion Animal Medicine, vol. 25, no. 1, pp. 53-58, 2010.

[37] C. A. Smith, C. T. Collins, C. A. Crowther, and K. M. Levett, "Acupuncture or acupressure for pain management in labour," Cochrane Database of Systematic Reviews, no. 7, article CD009232, 2011.

[38] F. C. Chang, H. Y. Tsai, M. C. Yu, P. L. Yi, and J. G. Lin, “The central serotonergic system mediates the analgesic effect of electroacupuncture on Zusanli (ST36) acupoints," Journal of Biomedical Science, vol. 11, no. 2, pp. 179-185, 2004.

[39] Y. Z. Gao, S. Y. Guo, Q. Z. Yin, T. Hisamitsu, and X. H. Jiang, "An individual variation study of electroacupuncture analgesia in rats using microarray," American Journal of Chinese Medicine, vol. 35, no. 5, pp. 767-778, 2007.

[40] Y. Chae, H. J. Park, D. H. Hahm, S. H. Yi, and H. Lee, "Individual differences of acupuncture analgesia in humans using cDNA microarray," Journal of Physiological Sciences, vol. 56, no. 6, pp. 425-431, 2006.

[41] X. Ding, J. Yu, T. Yu, Y. Fu, and J. Han, "Acupuncture regulates the aging-related changes in gene profile expression of the hippocampus in senescence-accelerated mouse (SAMP10)," Neuroscience Letters, vol. 399, no. 1-2, pp. 11-16, 2006.

[42] M. Li and Y. Zhang, "Modulation of gene expression in cholesterol-lowering effect of electroacupuncture at Fenglong acupoint (ST40): a cDNA microarray study," International Journal of Molecular Medicine, vol. 19, no. 4, pp. 617629, 2007.

[43] Z. R. Vlahcevic, S. K. Jairath, D. M. Heuman et al., "Transcriptional regulation of hepatic sterol 27-hydroxylase by bile acids," American Journal of Physiology, vol. 270, no. 4, pp. G646-G652, 1996.

[44] H. Wolters, B. M. Elzinga, J. F. W. Baller et al., "Effects of bile salt flux variations on the expression of hepatic bile salt transporters in vivo in mice," Journal of Hepatology, vol. 37, no. 5, pp. 556-563, 2002.

[45] C. Tan, J. Wang, W. Feng, W. Ding, and M. Wang, "Preliminary correlation between warm needling treatment for knee osteoarthritis of deficiency-cold syndrome and metabolic functional genes and pathways," JAMS Journal of Acupuncture and Meridian Studies, vol. 3, no. 3, pp. 173-180, 2010.

[46] X. Y. Wang, X. L. Li, S. Q. Hong, Y. B. Xi, and T. H. Wang, "Electroacupuncture induced spinal plasticity is linked to multiple gene expressions in dorsal root deafferented rats," Journal of Molecular Neuroscience, vol. 37, no. 2, pp. 97-110, 2009.

[47] J. Ko, D. S. Na, H. L. Young et al., “cDNA microarray analysis of the differential gene expression in the neuropathic pain and electroacupuncture treatment models," Journal of Biochemistry and Molecular Biology, vol. 35, no. 4, pp. 420427, 2002.

[48] W. Dauer and S. Przedborski, "Parkinson's disease: mechanisms and models," Neuron, vol. 39, no. 6, pp. 889-909, 2003.

[49] Y. G. Choi, S. Yeo, Y. M. Hong, S. H. Kim, and S. Lim, "Changes of gene expression profiles in the cervical spinal cord by acupuncture in an MPTP-intoxicated mouse model: microarray analysis," Gene, vol. 481, no. 1, pp. 7-16, 2011.

[50] Y. G. Choi, S. Yeo, Y. M. Hong, and S. Lim, "Neuroprotective changes of striatal degeneration-related gene expression by acupuncture in an MPTP mouse model of Parkinsonism: microarray analysis," Cellular and Molecular Neurobiology, vol. 31, no. 3, pp. 377-391, 2011. 
[51] M. S. Hong, H. K. Park, J. S. Yang et al., "Gene expression profile of acupuncture treatment in 1-methyl-4-phenyl-1,2, 3,6- tetrahydropyridine-induced Parkinson's disease model," Neurological Research, vol. 32, Supplement 1, pp. S74-S78, 2010.

[52] M. A. Noureddine, Y. J. Li, J. M. van der Walt et al., "Genomic convergence to identify candidate genes for Parkinson's disease: SAGE analysis of the substantia nigra," Movement Disorders, vol. 20, no. 10, pp. 1299-1309, 2005.

[53] C. K. Kim, G. S. Choi, S. D. Oh et al., "Electroacupuncture up-regulates natural killer cell activity: identification of genes altering their expressions in electroacupuncture induced upregulation of natural killer cell activity," Journal of Neuroimmunology, vol. 168, no. 1-2, pp. 144-153, 2005.

[54] S. K. Kim, J. Kim, E. Ko et al., "Gene expression profile of the hypothalamus in DNP-KLH immunized mice following electroacupuncture stimulation," Evidence-Based Complementary and Alternative Medicine, vol. 2011, Article ID 508689, 8 pages, 2011.

[55] S. H. Sohn, S. K. Kim, E. Ko et al., "The genomewide expression profile of electroacupuncture in DNP-KLH immunized mice," Cellular and Molecular Neurobiology, vol. 30, no. 4, pp. 631-640, 2010.

[56] H. S. Shiue, Y. S. Lee, C. N. Tsai, Y. M. Hsueh, J. R. Sheu, and H. H. Chang, "DNA microarray analysis of the effect on inflammation in patients treated with acupuncture for allergic rhinitis," Journal of Alternative and Complementary Medicine, vol. 14, no. 6, pp. 689-698, 2008.

[57] H. S. Shiue, Y. S. Lee, C. N. Tsai, Y. M. Hsueh, J. R. Sheu, and H. H. Chang, "Gene expression profile of patients with phadiatop-positive and -negative allergic rhinitis treated with acupuncture," Journal of Alternative and Complementary Medicine, vol. 16, no. 1, pp. 59-68, 2010.

[58] I. M. Cojocaru, M. Cojocaru, R. Tănǎsescu et al., "Changes in plasma levels of complement in patients with acute ischemic stroke," Romanian Journal of Internal Medicine, vol. 46, no. 1, pp. 77-80, 2008.

[59] W. J. Li, S. Q. Pan, Y. S. Zeng et al., "Identification of acupuncture-specific proteins in the process of electroacupuncture after spinal cord injury," Neuroscience Research, vol. 67, no. 4, pp. 307-316, 2010.

[60] C. P. M. Reutelingsperger and W. L. Van Heerde, "Annexin V, the regulator of phosphatidylserine-catalyzed inflammation and coagulation during apoptosis," Cellular and Molecular Life Sciences, vol. 53, no. 6, pp. 527-532, 1997.

[61] L. H. Wang and S. M. Strittmatter, "A family of rat CRMP genes is differentially expressed in the nervous system," Journal of Neuroscience, vol. 16, no. 19, pp. 6197-6207, 1996.

[62] J. R. Siebert, F. A. Middleton, and D. J. Stelzner, "Long descending cervical propriospinal neurons differ from thoracic propriospinal neurons in response to low thoracic spinal injury," BMC Neuroscience, vol. 11, article 148, 2010.

[63] S. Jeon, J. K. Youn, S. T. Kim et al., "Proteomic analysis of the neuroprotective mechanisms of acupuncture treatment in a Parkinson's disease mouse model," Proteomics, vol. 8, no. 22, pp. 4822-4832, 2008.

[64] S. T. Kim, W. Moon, Y. Chae, Y. J. Kim, H. Lee, and H. J. Park, "The effect of electroaucpuncture for 1-methyl-4-phenyl$1,2,3,6$ - tetrahydropyridine-induced proteomic changes in the mouse striatum," Journal of Physiological Sciences, vol. 60, no. 1, pp. 27-34, 2010.

[65] D. Sliva, "Cellular and physiological effects of Ganoderma lucidum (Reishi)," Mini-Reviews in Medicinal Chemistry, vol. 4, no. 8, pp. 873-879, 2004.
[66] C. Y. Lai, J. T. Hung, H. H. Lin et al., "Immunomodulatory and adjuvant activities of a polysaccharide extract of Ganoderma lucidum in vivo and in vitro," Vaccine, vol. 28, no. 31, pp. 4945-4954, 2010.

[67] Y. L. Lin, S. S. Lee, S. M. Hou, and B. L. Chiang, "Polysaccharide purified from Ganoderma lucidum induces gene expression changes in human dendritic cells and promotes T helper 1 immune response in BALB/c mice," Molecular Pharmacology, vol. 70, no. 2, pp. 637-644, 2006.

[68] H. R. Lemmon, J. Sham, L. A. Chau, and J. Madrenas, "High molecular weight polysaccharides are key immunomodulators in North American ginseng extracts: characterization of the ginseng genetic signature in primary human immune cells," Journal of Ethnopharmacology, vol. 142, no. 1, pp. 1$13,2012$.

[69] C. H. Cheng, A. Y. Leung, and C. F. Chen, "The effects of two different ganoderma species (Lingzhi) on gene expression in human monocytic THP-1 cells," Nutrition and Cancer, vol. 62, no. 5, pp. 648-658, 2010.

[70] J. Wu, M. Zhang, H. Jia et al., "Protosappanin A induces immunosuppression of rats heart transplantation targeting T cells in grafts via NF- $\kappa$ B pathway," Naunyn-Schmiedeberg's Archives of Pharmacology, vol. 381, no. 1, pp. 83-92, 2010.

[71] K. C. Cheng, H. C. Huang, J. H. Chen et al., "Ganoderma lucidum polysaccharides in human monocytic leukemia cells: from gene expression to network construction," BMC Genomics, vol. 8, article 411, 2007.

[72] Q. Zhang, F. Wei, C. C. Fong et al., "Transcriptional profiling of human skin fibroblast cell line Hs27 induced by herbal formula Astragali Radix and Rehmanniae Radix," Journal of Ethnopharmacology, vol. 138, no. 3, pp. 668-675, 2011.

[73] H. Zhao, J. Deneau, G. O. Che et al., "Angelica sinensis isolate SBD. 4: composition, gene expression profiling, mechanism of action and effect on wounds, in rats and humans," European Journal of Dermatology, vol. 22, no. 1, pp. 58-67, 2012.

[74] Y. Sun, S. M. Y. Lee, Y. M. Wong et al., "Dosing effects of an antiosteoporosis herbal formula-a preclinical investigation using a rat model," Phytotherapy Research, vol. 22, no. 2, pp. 267-273, 2008.

[75] X. Luo, C. Z. Wang, J. Chen et al., "Characterization of gene expression regulated by American ginseng and ginsenoside Rg3 in human colorectal cancer cells," International Journal of Oncology, vol. 32, no. 5, pp. 975-983, 2008.

[76] M. L. King and L. L. Murphy, "American ginseng (Panax Quinquefolius L.) extract alters mitogen-activated protein kinase cell signaling and inhibits proliferation of MCF-7cells," Journal of Experimental Therapeutics and Oncology, vol. 6, no. 2, pp. 147-155, 2007.

[77] A. Hara, N. Iizuka, Y. Hamamoto et al., "Molecular dissection of a medicinal herb with anti-tumor activity by oligonucleotide microarray," Life Sciences, vol. 77, no. 9, pp. 9911002, 2005.

[78] N. Iizuka, M. Oka, K. Yamamoto et al., "Identification of common or distinct genes related to antitumor activities of a medicinal herb and its major component by oligonucleotide microarray," International Journal of Cancer, vol. 107, no. 4, pp. 666-672, 2003.

[79] H. Wang, Y. Ye, S. Y. Pan et al., "Proteomic identification of proteins involved in the anticancer activities of oridonin in HepG2 cells," Phytomedicine, vol. 18, no. 2-3, pp. 163-169, 2011.

[80] Y. Xu, J. F. Chiu, Q. Y. He, and F. Chen, "Tubeimoside1 exerts cytotoxicity in heLa cells Through mitochondrial dysfunction and endoplasmic reticulum stress pathways," 
Journal of Proteome Research, vol. 8, no. 3, pp. 1585-1593, 2009.

[81] Z. X. Cheng, B. R. Liu, X. P. Qian et al., "Proteomic analysis of anti-tumor effects by Rhizoma Paridis total saponin treatment in HepG2 cells," Journal of Ethnopharmacology, vol. 120, no. 2, pp. 129-137, 2008.

[82] P. Y. K. Yue, D. Y. L. Wong, W. Y. Ha et al., "Elucidation of the mechanisms underlying the angiogenic effects of ginsenoside Rg1 in vivo and in vitro," Angiogenesis, vol. 8, no. 3, pp. 205216, 2005.

[83] V. B. Konkimalla, M. Blunder, B. Korn et al., "Effect of artemisinins and other endoperoxides on nitric oxide-related signaling pathway in RAW 264.7 mouse macrophage cells," Nitric Oxide, vol. 19, no. 2, pp. 184-191, 2008.

[84] S. Y. Su, C. Y. Cheng, T. H. Tsai, C. Y. Hsiang, T. Y. Ho, and C. L. Hsieh, "Paeonol attenuates $\mathrm{H}_{2} \mathrm{O}_{2}$-induced NF- $\kappa$ Bassociated amyloid precursor protein expression," American Journal of Chinese Medicine, vol. 38, no. 6, pp. 1171-1192, 2010.

[85] X. Wang, Y. Wang, M. Jiang et al., "Differential cardioprotective effects of salvianolic acid and tanshinone on acute myocardial infarction are mediated by unique signaling pathways," Journal of Ethnopharmacology, vol. 135, no. 3, pp. 662-671, 2011.

[86] W. Y. Lo, F. J. Tsai, C. H. Liu et al., "Uncaria rhynchophylla upregulates the expression of MIF and cyclophilin A in kainic acid-induced epilepsy rats: a proteomic analysis," American Journal of Chinese Medicine, vol. 38, no. 4, pp. 745-759, 2010.

[87] Y. C. Hung, P. W. Wang, and T. L. Pan, "Functional proteomics reveal the effect of Salvia miltiorrhiza aqueous extract against vascular atherosclerotic lesions," Biochimica et Biophysica Acta, vol. 1804, no. 6, pp. 1310-1321, 2010.

[88] Y. C. Hung, P. W. Wang, T. L. Pan, G. Bazylak, and Y. L. Leu, "Proteomic screening of antioxidant effects exhibited by Radix Salvia miltiorrhiza aqueous extract in cultured rat aortic smooth muscle cells under homocysteine treatment," Journal of Ethnopharmacology, vol. 124, no. 3, pp. 463-474, 2009.

[89] H. Zhao, R. Mortezaei, Y. Wang, X. Sheng, F. Aria, and K. Bojanowski, "SBD.4 stimulates regenerative processes in vitro, and wound healing in genetically diabetic mice and in human skin/severe-combined immunodeficiency mouse chimera," Wound Repair and Regeneration, vol. 14, no. 5, pp. 593-601, 2006.

[90] C. Prost-Squarcioni, S. Fraitag, M. Heller, and N. Boehm, "Functional histology of dermis," Annales De Dermatologie Et De Venereologie, vol. 135, no. 1, Part 2, pp. 1-20, 2008.

[91] A. R. Saltiel, "New perspectives into the molecular pathogenesis and treatment of type 2 diabetes," Cell, vol. 104, no. 4, pp. 517-529, 2001.

[92] R. S. Lindsay, T. Funahashi, R. L. Hanson et al., "Adiponectin and development of type 2 diabetes in the Pima Indian population," The Lancet, vol. 360, no. 9326, pp. 57-58, 2002.

[93] Y. Fu, N. Luo, R. L. Klein, and W. T. Garvey, "Adiponectin promotes adipocyte differentiation, insulin sensitivity, and lipid accumulation," Journal of Lipid Research, vol. 46, no. 7, pp. 1369-1379, 2005.

[94] J. W. Hsu, H. C. Huang, S. T. Chen, C. H. Wong, and H. F. Juan, "Ganoderma lucidum polysaccharides induce macrophage-like differentiation in human leukemia THP1 cells via caspase and p53 activation," Evidence-Based Complementary and Alternative Medicine, vol. 2011, Article ID 358717, 13 pages, 2011.
[95] J. Jiang, I. Eliaz, and D. Sliva, "Suppression of growth and invasive behavior of human prostate cancer cells by ProstaCaid: mechanism of activity," International Journal of Oncology, vol. 38, no. 6, pp. 1675-1682, 2011.

[96] J. Jiang and D. Sliva, "Novel medicinal mushroom blend suppresses growth and invasiveness of human breast cancer cells," International Journal of Oncology, vol. 37, no. 6, pp. 1529-1536, 2010.

[97] S. M. Y. Lee, M. L. Y. Li, Y. C. Tse et al., "Paeoniae Radix, a Chinese herbal extract, inhibit hepatoma cells growth by inducing apoptosis in a p53 independent pathway," Life Sciences, vol. 71, no. 19, pp. 2267-2277, 2002.

[98] H. Li, N. Takai, A. Yuge et al., "Novel target genes responsive to the anti-growth activity of triptolide in endometrial and ovarian cancer cells," Cancer Letters, vol. 297, no. 2, pp. 198206, 2010.

[99] A. N. Pham, P. E. Blower, O. Alvarado, R. Ravula, P. W. Gout, and Y. Huang, "Pharmacogenomic approach reveals a role for the xc-cystine/glutamate antiporter in growth and celastrol resistance of glioma cell lines," Journal of Pharmacology and Experimental Therapeutics, vol. 332, no. 3, pp. 949-958, 2010.

[100] E. Wang, S. Bussom, J. Chen et al., "Interaction of a traditional Chinese Medicine (PHY906) and CPT-11 on the inflammatory process in the tumor microenvironment," BMC Medical Genomics, vol. 4, article 38, 2011.

[101] J. H. Yoo, H. C. Kwon, Y. J. Kim, J. H. Park, and H. O. Yang, "KG-135, enriched with selected ginsenosides, inhibits the proliferation of human prostate cancer cells in culture and inhibits xenograft growth in athymic mice," Cancer Letters, vol. 289, no. 1, pp. 99-110, 2010.

[102] S. P. Hussain, G. E. Trivers, L. J. Hofseth et al., "Nitric oxide, a mediator of inflammation, suppresses tumorigenesis," Cancer Research, vol. 64, no. 19, pp. 6849-6853, 2004.

[103] J. X. Kang, J. Liu, J. Wang, C. He, and F. P. Li, “The extract of huanglian, a medicinal herb, induces cell growth arrest and apoptosis by upregulation of interferon- $\beta$ and TNF- $\alpha$ in human breast cancer cells," Carcinogenesis, vol. 26, no. 11, pp. 1934-1939, 2005.

[104] L. S. Chan, P. Y. K. Yue, N. K. Mak, and R. N. S. Wong, "Role of MicroRNA-214 in ginsenoside-Rg1-induced angiogenesis," European Journal of Pharmaceutical Sciences, vol. 38, no. 4, pp. 370-377, 2009.

[105] H. Yaoita, K. Ogawa, K. Maehara, and Y. Maruyama, "Apoptosis in relevant clinical situations: contribution of apoptosis in myocardial infarction," Cardiovascular Research, vol. 45, no. 3, pp. 630-641, 2000.

[106] K. Ito, X. Yan, M. Tajima, Z. Su, W. H. Barry, and B. H. Lorell, "Contractile reserve and intracellular calcium regulation in mouse myocytes from normal and hypertrophied failing hearts," Circulation Research, vol. 87, no. 7, pp. 588-595, 2000.

[107] D. Praticò, "Oxidative stress hypothesis in Alzheimer's disease: a reappraisal," Trends in Pharmacological Sciences, vol. 29, no. 12, pp. 609-615, 2008.

[108] F. Wang, R. Ma, and L. Yu, "Role of mitochondria and mitochondrial cytochrome $\mathrm{c}$ in tubeimoside I-mediated apoptosis of human cervical carcinoma HeLa cell line," Cancer chemotherapy and pharmacology., vol. 57, no. 3, pp. 389-399, 2006.

[109] J. Lee, D. Son, P. Lee et al., "Protective effect of methanol extract of Uncaria rhynchophylla against excitotoxicity induced by N-methyl-D-aspartate in rat hippocampus," Journal Pharmacological Sciences, vol. 92, no. 1, pp. 70-73, 2003. 
[110] H. Li, Y. Gao, C. D. Freire, M. K. Raizada, G. M. Toney, and C. Sumners, "Macrophage migration inhibitory factor in the PVN attenuates the central pressor and dipsogenic actions of angiotensin II," The FASEB Journal, vol. 20, no. 10, pp. 17481750, 2006.

[111] J. Liu, J. D. Farmer Jr., W. S. Lane, J. Friedman, I. Weissman, and S. L. Schreiber, "Calcineurin is a common target of cyclophilin-cyclosporin A and FKBP-FK506 complexes," Cell, vol. 66, no. 4, pp. 807-815, 1991.

[112] S. G. Oliver, M. K. Winson, D. B. Kell, and F. Baganz, "Systematic functional analysis of the yeast genome," Trends in Biotechnology, vol. 16, no. 9, pp. 373-378, 1998.

[113] S. Agnolet, J. W. Jaroszewski, R. Verpoorte, and D. Staerk, "1H NMR-based metabolomics combined with HPLC-PDAMS-SPE-NMR for investigation of standardized Ginkgo biloba preparations," Metabolomics, vol. 6, no. 2, pp. 292302, 2010.

[114] Q. Zhang, G. J. Wang, J. Y. A et al., "Application of GC/MS-based metabonomic profiling in studying the lipidregulating effects of Ginkgo biloba extract on diet-induced hyperlipidemia in rats," Acta Pharmacologica Sinica, vol. 30, no. 12, pp. 1674-1687, 2009.

[115] G. Tan, Z. Lou, J. Jing et al., "Screening and analysis of aconitum alkaloids and their metabolites in rat urine after oral administration of aconite roots extract using LCTOFMS-based metabolomics," Biomedical Chromatography, vol. 25, no. 12, pp. 1343-1351, 2011.

[116] S. Yan, B. Wu, Z. Lin et al., "Metabonomic characterization of aging and investigation on the anti-aging effects of total flavones of Epimedium," Molecular BioSystems, vol. 5, no. 10, pp. 1204-1213, 2009.

[117] Q. Zhang, F. Zuo, N. Nakamura, C. M. Ma, and M. Hattori, "Metabolism and pharmacokinetics in rats of ganoderiol F, a highly cytotoxic and antitumor triterpene from Ganoderma lucidum," Journal of Natural Medicines, vol. 63, no. 3, pp. 304-310, 2009. 


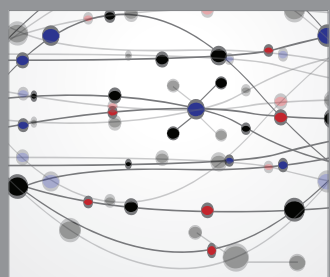

The Scientific World Journal
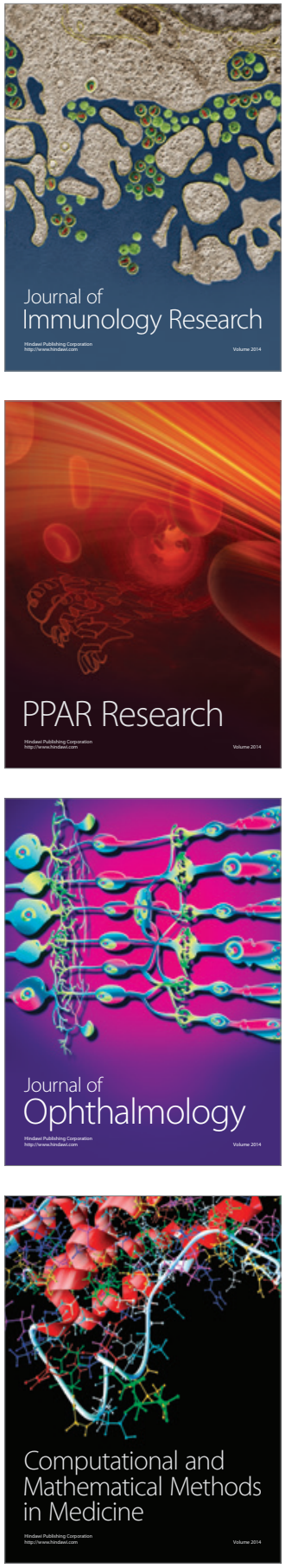

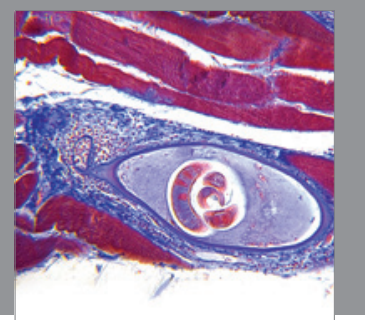

Gastroenterology

Research and Practice
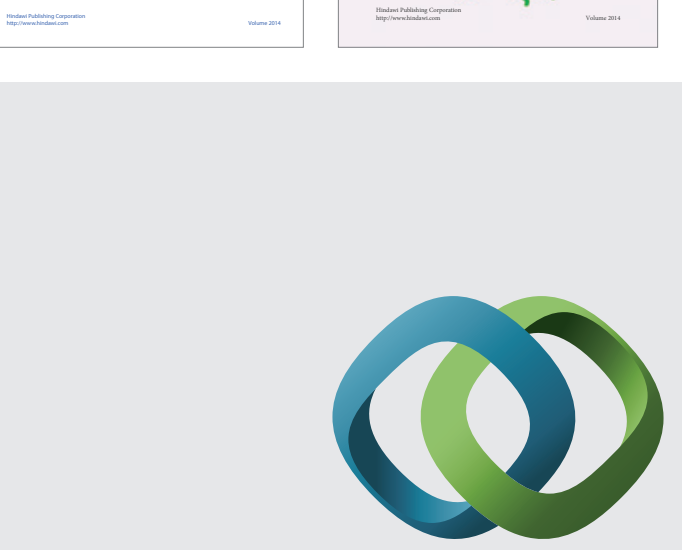

\section{Hindawi}

Submit your manuscripts at

http://www.hindawi.com
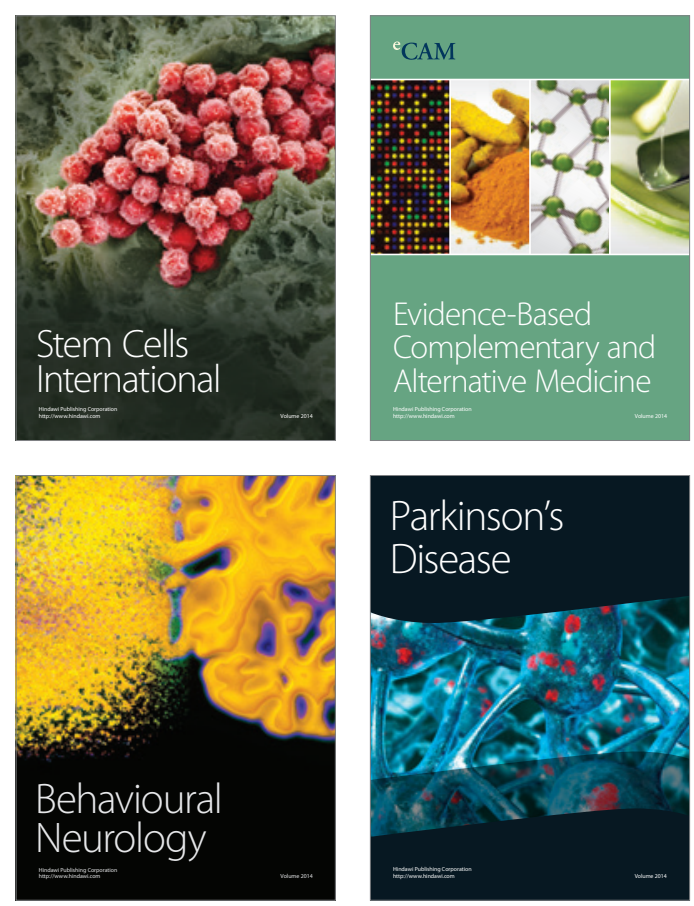

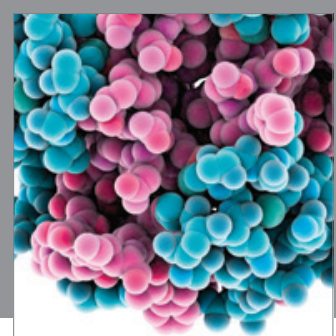

Journal of
Diabetes Research

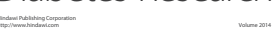

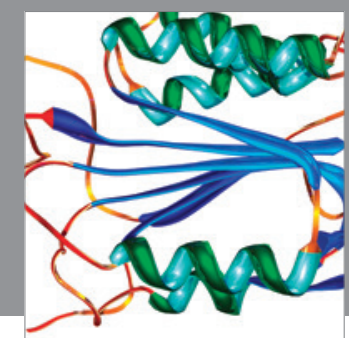

Disease Markers
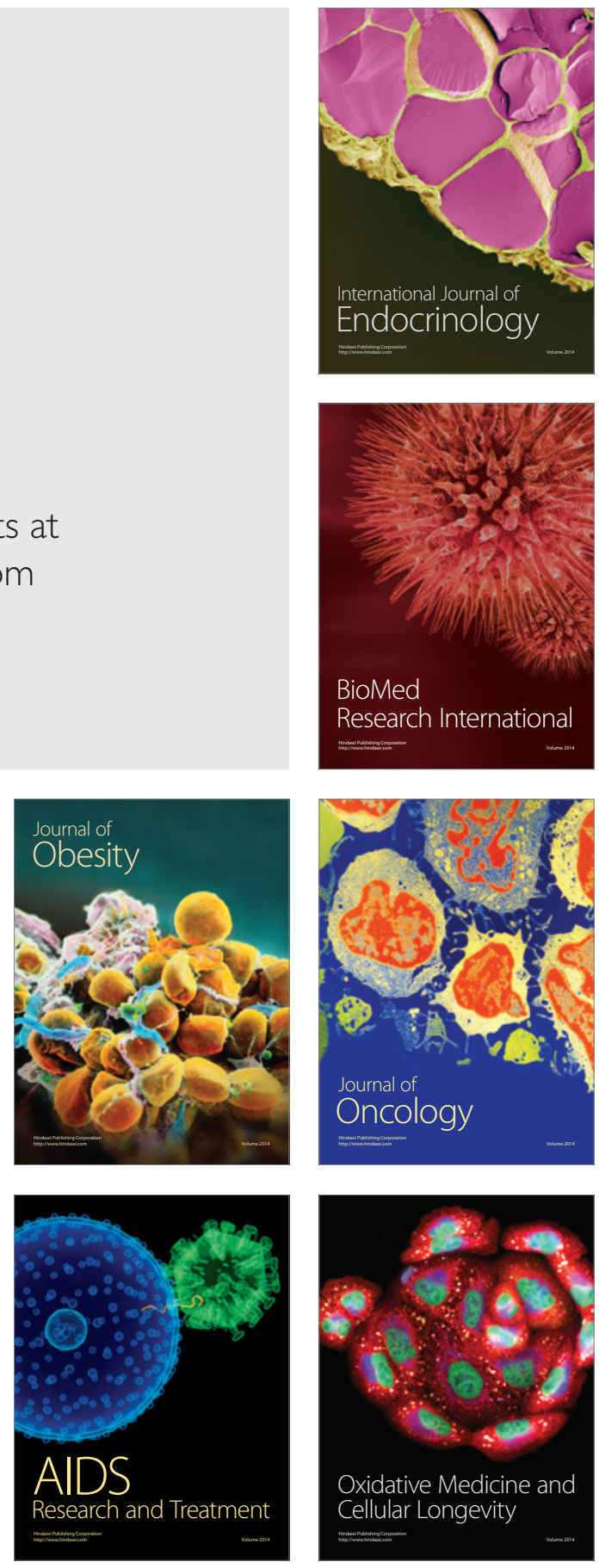